\title{
DINÂMICA DO ENRAIZAMENTO DE MICROESTACAS E MINIESTACAS DE CLONES DE Eucalyptus grandis ${ }^{1}$
}

\author{
Miranda Titon ${ }^{2}$, Aloisio Xavier ${ }^{3}$ e Wagner Campos Otoni ${ }^{4}$
}

\begin{abstract}
RESUMO - O presente estudo teve por objetivo avaliar a dinâmica de enraizamento de microestacas e miniestacas, mediante o acompanhamento da emissão e do desenvolvimento de raízes de quatro clones de Eucalyptus grandis. Foram utilizadas microestacas provenientes de brotações coletadas em plantas rejuvenescidas por micropropagação e miniestacas oriundas de brotações coletadas de miniestacas enraizadas originadas de mudas propagadas pelo processo de estaquia convencional. Os resultados indicaram a maior habilidade de enraizamento das microestacas em relação às miniestacas, evidenciada através do número de raízes/estaca, comprimento total de raiz/estaca, comprimento da maior raiz/estaca, comprimento médio de raízes/estaca e peso de matéria seca de raízes.
\end{abstract}

Palavras-chave: Miniestaquia, microestaquia, silvicultura clonal e rejuvenescimento.

\section{ROOTING DYNAMICS OF MICROCUTTINGS AND MINICUTTINGS OF Eucalyptus grandis CLONES}

\begin{abstract}
The aim of this work was to evaluate the dynamics of microcutting and minicutting techniques during rooting process, by monitoring root emergence and development in microcuttings and minicuttings of four Eucalyptus grandis clones. Microcuttings were obtained from in vitro rejuvenated plant-derived sprouts, whereas minicuttings from rooted sprouts derived from plants propagated through conventional cutting technique. The results suggest the greater rooting ability of the microcuttings as compared to the minicuttings, evidenced by the number of roots/cuttings, total root/cutting length, largest root/cutting length, mean length of roots/cutting and dry weight of roots.
\end{abstract}

Key words: Minicutting technique, microcutting technique, clonal forestry, rejuvenation.

\section{INTRODUÇÃO}

Em espécies lenhosas a aptidão à propagação vegetativa está associada ao grau de maturação, em que a fase juvenil, na maioria das plantas, apresenta maior potencial de enraizamento que a fase adulta (Bonga, 1982; George, 1993; Hartmann et al., 1997), expresso tanto em porcentagem quanto pelo tempo requerido para verificação do evento e, ainda, pela qualidade das próprias raízes (Gomes, 1987).

Na silvicultura clonal, o conhecimento de órgãos e tecidos juvenis é de relevante importância, visto que na propagação massal de clones selecionados este tipo de propágulo apresenta maior facilidade de enraizamento, aliado à reprodução de fenótipos desejáveis de mudas com características juvenis (Gomes, 1987; Ahuja, 1993).

Em vista das dificuldades de enraizamento apresentadas pelo material maduro, o rejuvenescimento de células e tecidos é, provavelmente, um dos mais importantes aspectos para o alcance efetivo da clonagem (Bonga, 1982), podendo ser considerado uma forma de reverter as plantas do estádio maduro para o juvenil, restaurando, desta maneira, sua competência ao enraizamento (Hackett \& Murray, 1993).

1 Recebido para publicação em 29.01.2002.

Aceito para publicação em 3.12.2002.

2 Engenheira Florestal, M.S.; ${ }^{3}$ Professor do Departamento de Engenharia Florestal da Universidade Federal de Viçosa - UFV, 36571-000 Viçosa-MG; ${ }^{4}$ Professor do Departamento de Biologia Vegetal da UFV. 
Diversas práticas têm sido adotadas para obter brotações juvenis ou promover o rejuvenescimento de tecidos adultos, podendo ser realizadas tanto em condições in vivo quanto in vitro (Franclet et al., 1987). Uma das práticas de rejuvenescimento utilizadas em plantas lenhosas tem sido a micropropagação por subcultivos sucessivos in vitro em meio de cultura contendo citocinina (Gonçalves, 1982; Bonga \& Von Aderkas, 1992; Assis \& Teixeira, 1998; Grattapaglia \& Machado, 1998). A restauração de características juvenis, como o maior potencial de enraizamento, tem sido observada em Eucalyptus com o aumento do número de subcultivos (Hackett \& Murray, 1993; Zobel, 1993; Assis, 1996; Xavier \& Comério, 1996).

Dentro do processo de enraizamento de estacas de Eucalyptus, as técnicas de microestaquia (Assis et al., 1992; Xavier \& Comério, 1996) e, mais recentemente, a de miniestaquia (Xavier \& Wendling, 1998; Wendling et al., 2000) têm sido utilizadas com êxito na propagação de clones selecionados, o que possibilita consideráveis ganhos, decorrentes principalmente do aumento dos índices de enraizamento e da redução do tempo para formação da muda, pelo uso de propágulos com maior grau de juvenilidade.

Estudos realizados por Xavier et al. (2001) e Titon (2001), sobre enraizamento de microestacas e miniestacas de Eucalyptus, têm sinalizado o desempenho superior da microestaquia em relação à miniestaquia, principalmente em clones com maior dificuldade de enraizamento. No entanto, os fatores que determinam essa diferença ainda são pouco conhecidos, podendo estar associados ao maior grau de juvenilidade dos propágulos da microestaquia, o que acarretaria maior habilidade de desenvolvimento do sistema radicular.

Neste contexto, o presente estudo teve por objetivo avaliar a dinâmica de enraizamento de microestacas e miniestacas, mediante o acompanhamento da emissão e do desenvolvimento de raízes de quatro clones de Eucalyptus grandis W. Hill ex Maiden.

\section{MATERIAL E MÉTODOS}

Os clones de Eucalyptus utilizados no presente estudo foram provenientes da Empresa Celulose NipoBrasileira S.A. (CENIBRA), localizada no município de Belo Oriente-MG, sendo dois clones de Eucalyptus grandis (CC1 e CC8) e dois híbridos de Eucalyptus grandis - Rio Claro-SP (CC11 e CC12).
As mudas utilizadas na formação do jardim microclonal foram provenientes de material micropropagado, mediante a proliferação de gemas axilares, conforme detalhado em Titon (2001). As gemas alongadas in vitro foram transplantadas em casa de vegetação localizada no viveiro de pesquisas do Departamento de Engenharia Florestal da Universidade Federal de Viçosa, em ViçosaMG, para o enraizamento ex vitro. Após o enraizamento em casa de vegetação (permanência de 30 dias), a aclimatação em casa de sombra (permanência de dez dias) e a rustificação a pleno sol, as mudas micropropagadas, com altura variando de 10 a $12 \mathrm{~cm}$, tiveram seus ápices podados na altura de $8 \mathrm{~cm}$, para obtenção das microcepas, que forneceram as microestacas, conforme metodologia descrita por Xavier \& Comério (1996).

O jardim miniclonal foi constituído de minicepas obtidas pelo enraizamento de miniestacas oriundas das brotações de plantas propagadas pelo método da estaquia convencional, conforme a técnica de miniestaquia descrita por Xavier \& Wendling (1998) e Wendling (1999). As miniestacas enraizadas, ao atingirem de 10 a $12 \mathrm{~cm}$ de altura, tiveram seus ápices podados na altura de $8 \mathrm{~cm}$, constituindo, assim, as minicepas, que forneceram as brotações (miniestacas) para realização do experimento.

A partir de material vegetativo de microestacas e miniestacas, os jardins clonais foram instalados no viveiro florestal da Empresa Celulose Nipo-Brasileira (CENIBRA), em condições cobertas. Como recipientes para as microcepas e minicepas foram utilizados tubetes de plástico de $55 \mathrm{~cm}^{3}$, contendo substrato constituído de partes iguais de vermiculita de granulometria média e casca de arroz carbonizada. O sistema de manejo do jardim clonal foi o mesmo utilizado pela empresa, o qual foi composto por bandejas de aço inoxidável, sobre as quais permaneceram as microcepas e minicepas, acondicionadas em tubetes dispostos em bandejas de plástico rígido. A irrigação e a nutrição mineral foram efetuadas através de um sistema automatizado de fertirrigação por inundação, conforme procedimento utilizado pela empresa.

As microestacas e miniestacas, com 4 a $6 \mathrm{~cm}$ de tamanho, foram coletadas nos jardins microclonal e miniclonal e colocadas para enraizamento em casa de vegetação, em tubetes de plástico de $55 \mathrm{~cm}^{3}$, contendo substrato constituído de partes iguais de vermiculita de granulometria média e casca de arroz carbonizada. A nutrição mineral utilizada no substrato foi composta por 
superfosfato simples $\left(8 \mathrm{~kg} / \mathrm{m}^{3}\right)$ e pela solução de sulfato de amônio $\left(20 \mathrm{~kg} / \mathrm{m}^{3}\right)$, cloreto de potássio $\left(3,33 \mathrm{~kg} / \mathrm{m}^{3}\right)$, sulfato de zinco $\left(0,22 \mathrm{~kg} / \mathrm{m}^{3}\right)$, sulfato de cobre $\left(0,22 \mathrm{~kg} / \mathrm{m}^{3}\right)$ e ácido bórico $\left(0,39 \mathrm{~kg} / \mathrm{m}^{3}\right)$, sendo, desta solução, aplicados 51 por 1001 de substrato.

O enraizamento das microestacas e miniestacas foi observado durante a permanência em casa de vegetação, por meio de avaliações aos 10, 14, 17, 21, 24 e 28 dias, quando foram determinados o número de raízes $(\geq 2 \mathrm{~mm}$ de comprimento), o comprimento total de raízes (somatório dos valores de comprimento de cada raiz por miniestaca e microestaca enraizada), o comprimento da maior raiz e o comprimento médio das raízes das microestacas e miniestacas (média dos valores de comprimento das raízes por miniestaca e microestaca enraizada). Ao final dos 28 dias foi avaliado, também, o peso de matéria seca de raiz das microestacas e miniestacas.

O experimento foi instalado segundo o delineamento inteiramente casualizado, no esquema fatorial constituído de quatro clones e duas técnicas, em seis repetições e parcelas compostas de 32 plantas. Em cada avaliação aos $10,14,17,21,24$ e 28 dias, foram utilizadas duas microestacas/miniestacas.

\section{RESULTADOS E DISCUSSÃO}

Os resultados e as discussões a seguir buscam enfocar a avaliação da emissão e do desenvolvimento de raízes dos quatro clones de Eucalyptus grandis. No entanto, para dar subsídio a essa discussão, inicialmente são apresentadas informações adicionais referentes ao enraizamento desses clones.

De acordo com resultados apresentados por Titon (2001), os porcentuais médios de enraizamento obtidos aos 28 dias após o estaqueamento foram de 95,8 e 91,7\% para o clone $\mathrm{CC} 1 ; 100$ e $100 \%$ para o clone CC8; 92,7 e $68,8 \%$ para o clone $\mathrm{CC} 11$; e 87,5 e $90,6 \%$ para o clone $\mathrm{CC} 12$; na microestaquia e na miniestaquia, respectivamente. Observou-se que o porcentual de enraizamento do CC11, na miniestaquia, foi bem inferior ao dos demais clones, porém com a utilização da microestaquia houve aumento de $34,7 \%$ do índice de enraizamento em relação à miniestaquia.

Em relação às avaliações da dinâmica da emissão e do desenvolvimento de raízes, os resultados da análise de variância referente às características número de raízes, comprimento total de raízes, comprimento da maior raiz, comprimento médio de raízes e peso de matéria seca de raízes das microestacas e miniestacas, avaliadas aos 10 , 14, 17, 21, 24 e 28 dias após o estaqueamento, dos quatro clones de Eucalyptus, apresentaram efeito significativo da interação "Clone x Técnica" pelo teste $\mathrm{F}(\mathrm{P}<0,05)$, indicando respostas diferenciadas dos clones às técnicas utilizadas.

Em relação ao número de raízes, observou-se que na avaliação realizada aos dez dias após o estaqueamento os quatro clones já apresentavam raízes visíveis ou pontos de iniciação de raízes (Figura 1). O número médio de raízes emitidas por estaca, nos quatro clones, aumentou progressivamente até o $17^{\circ} \mathrm{dia}$, estabilizando-se posteriormente. As médias dos clones variaram entre 3,2 e 4,2 raízes/estaca, na microestaquia, e entre 3,0 e 3,5, na miniestaquia.

Com base na Figura 1, nota-se que o clone CC12 apresentou valores de número médio de raízes/estaca superiores aos dos demais clones, indicando variabilidade de resposta entre clones a esta característica. Observase, ainda, que o número de raízes/estaca observado para este clone e para o clone CC11, até a avaliação aos 17 dias, foi bastante superior na microestaquia.

Quanto à característica comprimento total de raízes, conforme apresentado na Figura 2, o aumento foi progressivo no decorrer das avaliações. O clone CC8 foi o que apresentou maiores valores, seguido do clone CC12, cujos valores foram bastante próximos entre si. Já nos clones $\mathrm{CC} 1$ e CC11, o comprimento total de raízes/estaca foi bastante inferior ao dos dois primeiros. Ao comparar as técnicas de microestaquia e miniestaquia, foram constatadas diferenças significativas no clone $\mathrm{CC} 11$, na maioria das idades, e no clone CC12, na idade de 14 dias, sendo os maiores valores observados na microestaquia.

Com relação ao comprimento da maior raiz (Figura 3), o comportamento foi semelhante ao comprimento total de raízes, devendo ser ressaltado que os clones CC1, CC8 e CC12 apresentaram valores bastante semelhantes entre si. Entre as técnicas foi observado que para o clone CC11, na maioria das idades, a microestaquia apresentou valores maiores que os da miniestaquia.

No que tange ao comprimento médio de raízes/ estaca (Figura 4), notou-se que, nas primeiras avaliações, o clone CC11 apresentou valores menores que os dos outros clones. No entanto, essas diferenças foram tornando-se menos evidentes nas avaliações posteriores. Em termos gerais, no decorrer das avaliações realizadas 
observou-se que os clones CC1 e CC11 apresentaram menor número de raízes/estaca, o que resultou em menor comprimento total de raízes/estaca, comparado com os dos clones CC8 e CC12, uma vez que não houve grande variação entre os clones no comprimento da maior raiz e no comprimento médio de raiz/estaca.

O peso de matéria seca de raízes, aos 28 dias de idade das microestacas e miniestacas, variou entre os

\section{Clone CC1}

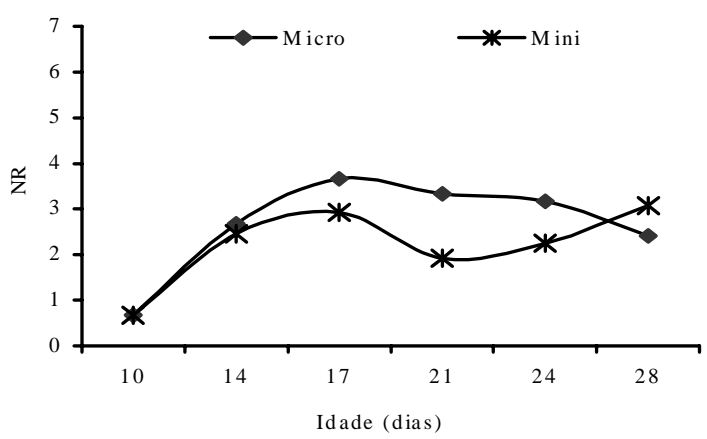

Clone CC11

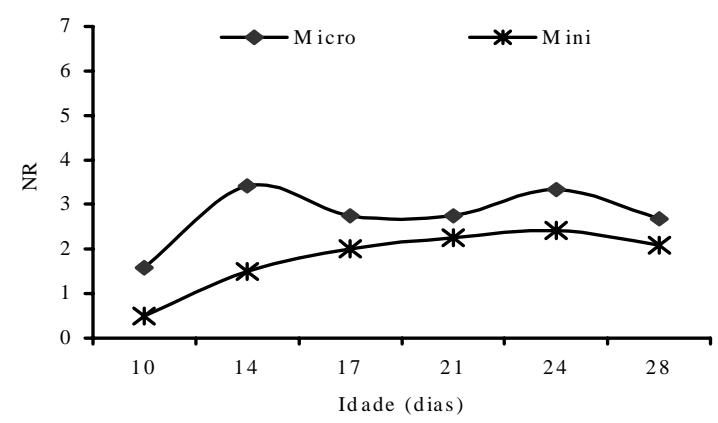

clones e entre as técnicas, sendo os resultados superiores para a microestaquia, na maioria dos clones, inclusive na média geral (Figura 5). Semelhantemente às outras características avaliadas, os clones CC8 e CC12 apresentaram maiores pesos de matéria seca de raízes, seguidos pelos clones CC1 e CC11, reforçando a importância do material genético na capacidade e velocidade de enraizamento de estacas (Gonçalves, 1982; Silva, 1990; Zobel, 1993).

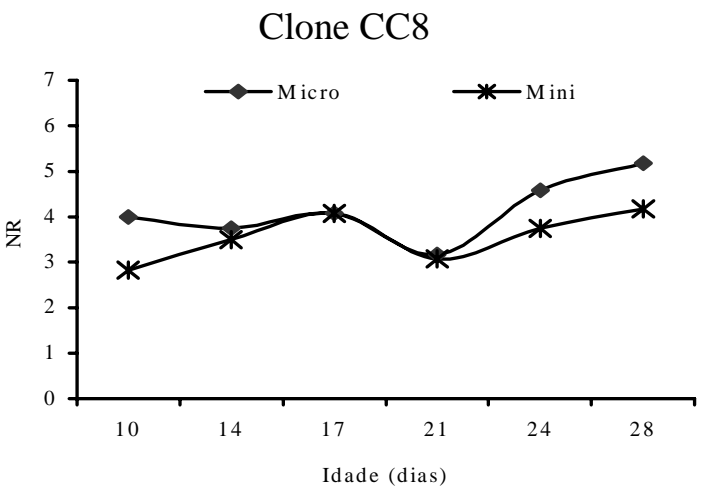

\section{Clone CC12}

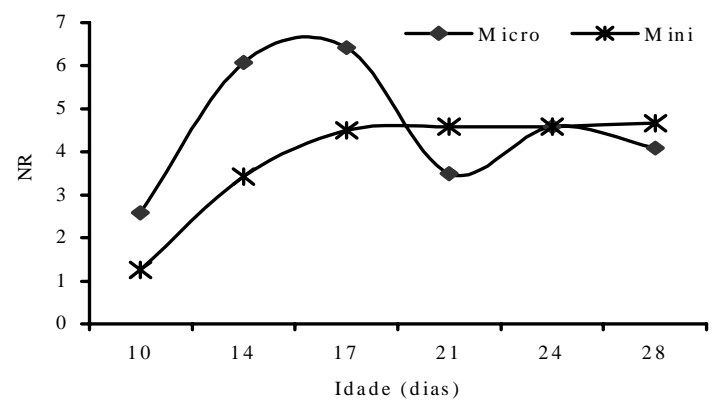

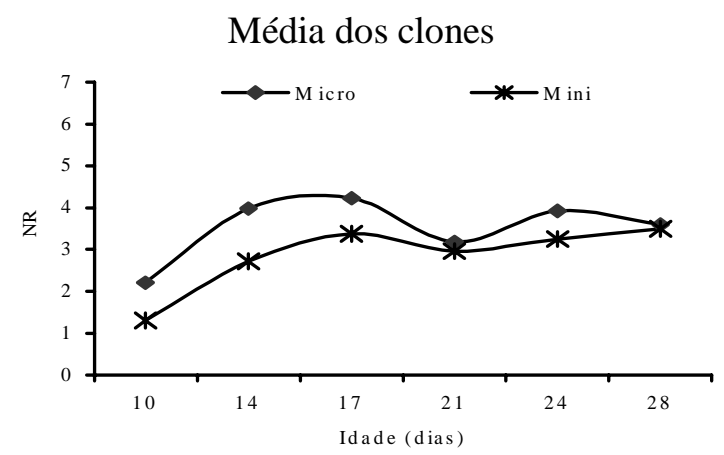

Figura 1 - Número de raízes (NR) emitidas pelas microestacas (Micro) e miniestacas (Mini) e médias de quatro clones de Eucalyptus grandis, avaliado aos 10, 14, 17, 21, 24 e 28 dias após o estaqueamento.

Figure 1 - Root number (NR) of microcuttings (Micro) and minicuttings (Mini) and overall means of four Eucalyptus grandis clones, evaluated at 10,14,17,21, 24 and 28 days of age. 


\section{Clone CC1}

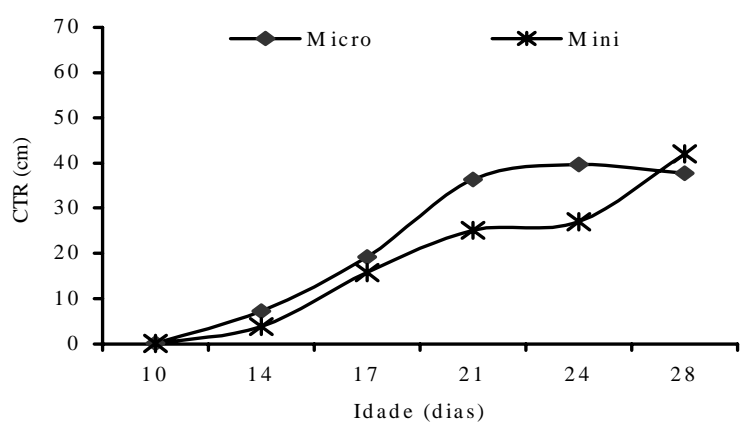

Clone CC11

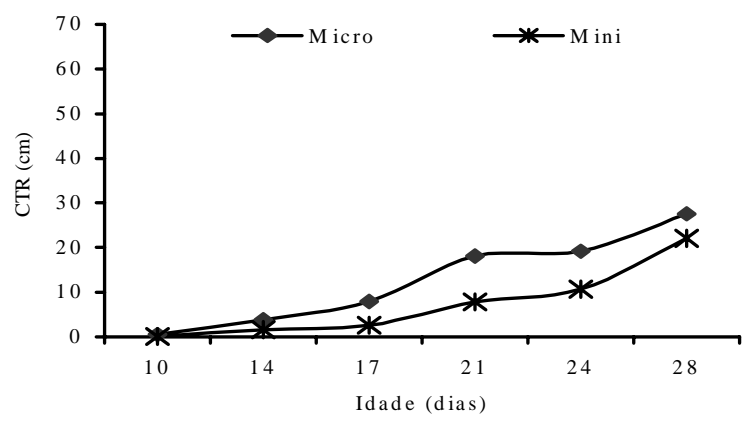

Clone CC8

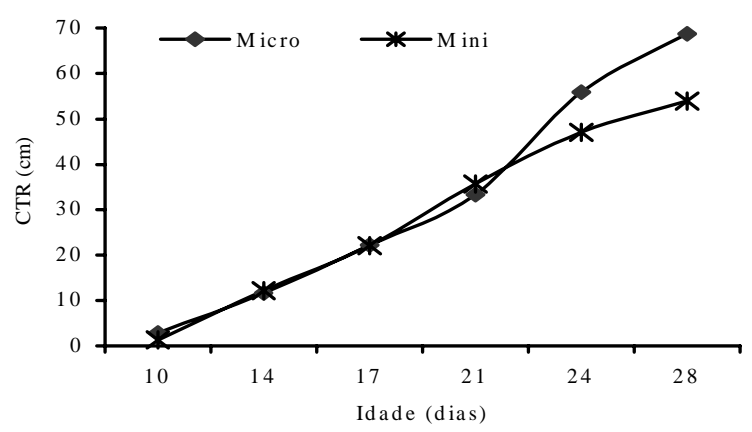

Clone CC12

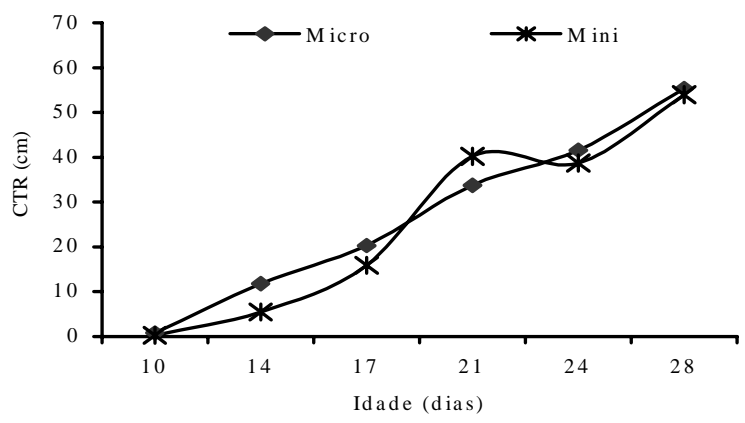

Média dos clones

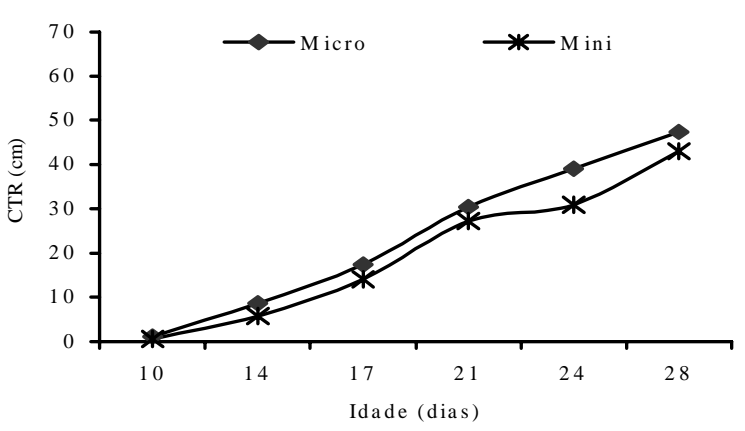

Figura 2 - Comprimento total de raízes (CTR) das microestacas (Micro) e miniestacas (Mini) e médias de quatro clones de Eucalyptus grandis, avaliado aos 10, 14, 17, 21, 24 e 28 dias após o estaqueamento.

Figure 2 - Total root length (CTR) of microcuttings (Micro) and minicuttings (Mini) and overall means of four Eucalyptus grandis clones, evaluated at 10,14, 17, 21, 24 and 28 days of age.

Em cada clone, observou-se que a maioria dos valores obtidos foi superior na microestaquia, principalmente nas avaliações iniciais, assim como no conjunto, quando se tratava das médias dos quatro clones. Considerando os clones estudados, os resultados indicaram a maior habilidade de enraizamento das microestacas em relação às miniestacas, evidenciada pelo número de raízes/estaca, comprimento total de raiz/estaca, comprimento da maior raiz/estaca, comprimento médio de raízes/estaca e peso de matéria seca de raízes. 
Clone CC1

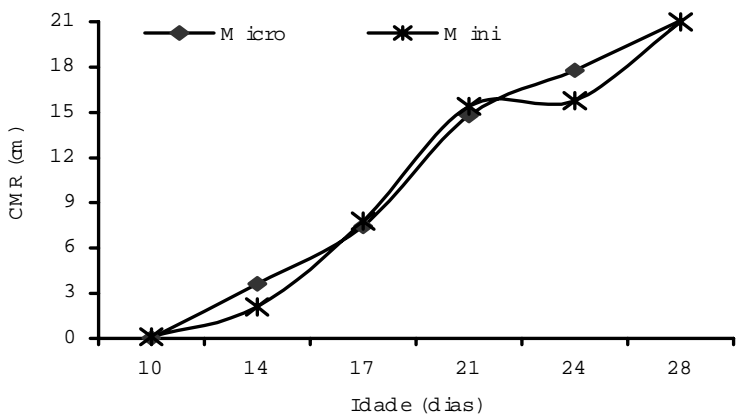

Clone CC11

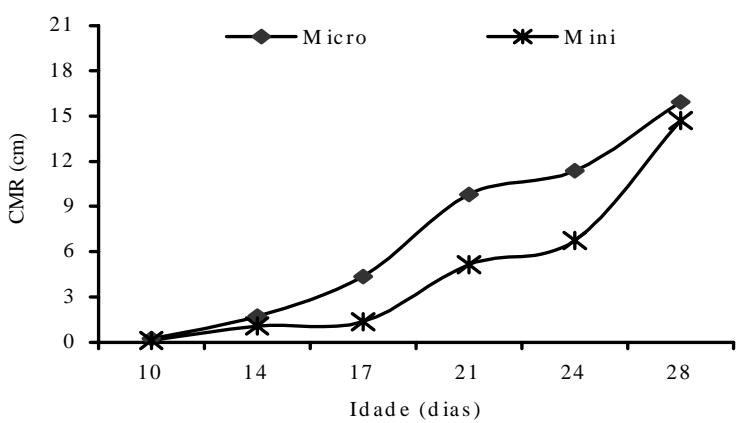

Clone CC8

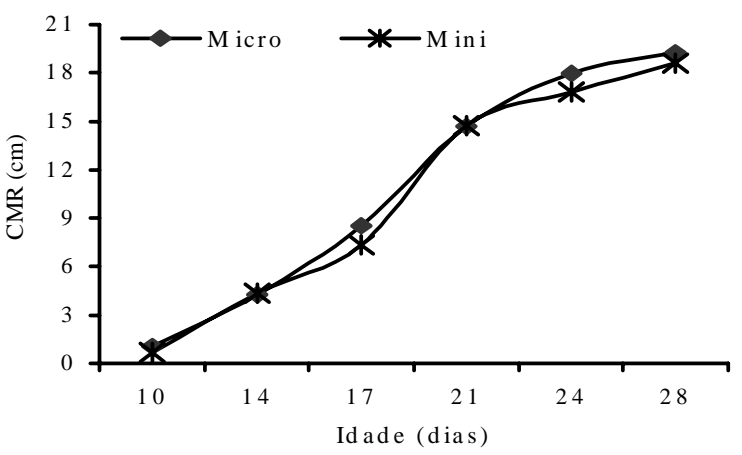

Clone CC12

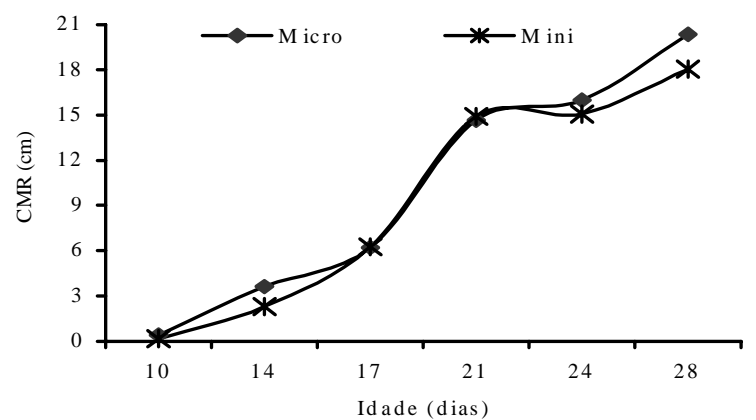

Média dos clones

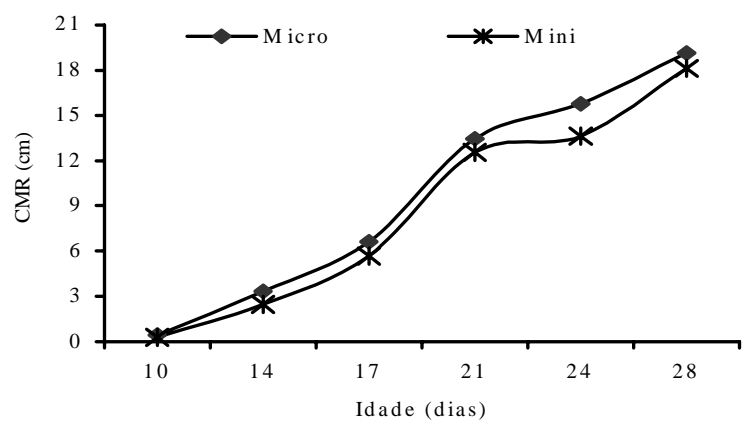

Figura 3 - Comprimento da maior raiz (CMR) das microestacas (Micro) e miniestacas (Mini) e médias de quatro clones de Eucalyptus grandis, avaliado aos 10, 14, 17, 21, 24 e 28 dias após o estaqueamento.

Figure 3-Length of largest root (CMR) of microcuttings (Micro) and minicuttings (Mini) and overall means of four Eucalyptus grandis clones, evaluated at 10, 14, 17, 21, 24 and 28 days of age.

Os resultados obtidos neste trabalho corroboram com os obtidos no enraizamento de microestacas e miniestacas, apresentados por Xavier et al. (2001), em que a microestaquia apresentou maior porcentual de enraizamento em relação à miniestaquia.
A maior habilidade de enraizamento das microestacas pode estar associada a efeitos de rejuvenescimento ou revigoramento dos clones pela micropropagação, concordando com a literatura que aborda aspectos relacionados à juvenilidade e maturação (Bonga, 1982; 
Gomes, 1987; Hackett, 1987; George, 1993; Greenwood \& Hutchison, 1993; Hartmann et al., 1997).

Esses resultados, em termos práticos, indicam que a microestaquia aumenta a eficiência do índice de enraizamento, principalmente para clones de difícil

\section{Clone CC1}

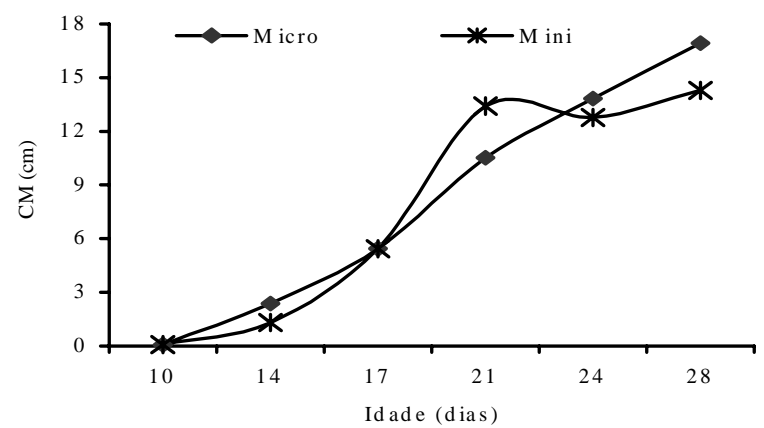

Clone CC11

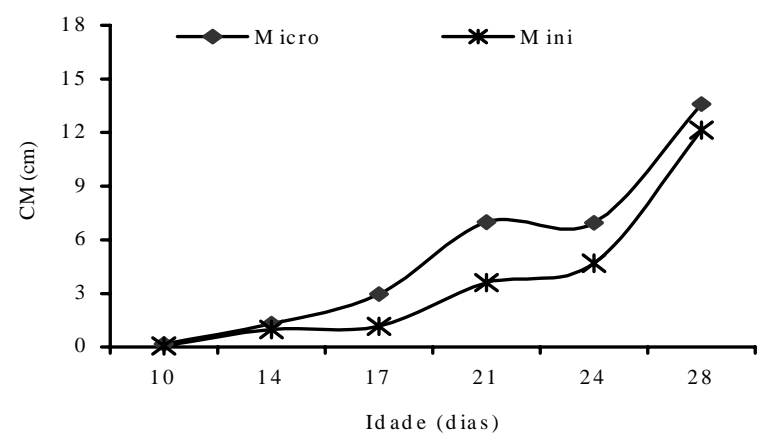

enraizamento, além de acelerar o processo de produção de mudas em viveiro, reduzindo o tempo de enraizamento em casa de vegetação, disponibilizando, assim, as estruturas de enraizamento mais rapidamente e, ao mesmo tempo, formando mudas com maior vigor vegetativo.
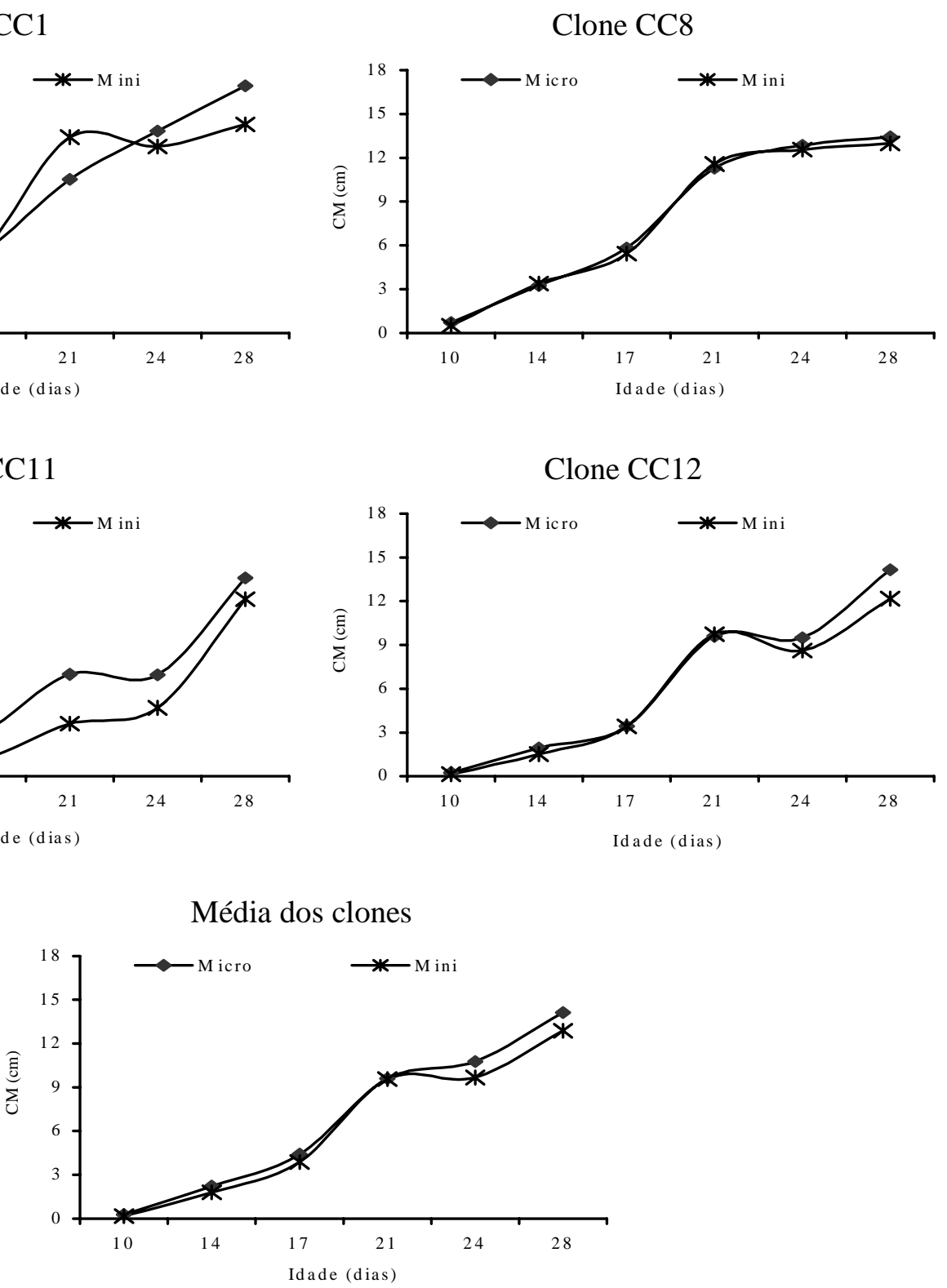

Figura 4 - Comprimento médio de raízes (CM) das microestacas (Micro) e miniestacas (Mini) e médias de quatro clones de Eucalyptus grandis, avaliado aos 10, 14, 17, 21, 24 e 28 dias após o estaqueamento.

Figure 4-Mean length of roots (CM) of microcuttings (Micro) and minicuttings (Mini) and overall means of four Eucalyptus grandis clones, evaluated at 10,14, 17, 21, 24 and 28 days of age. 


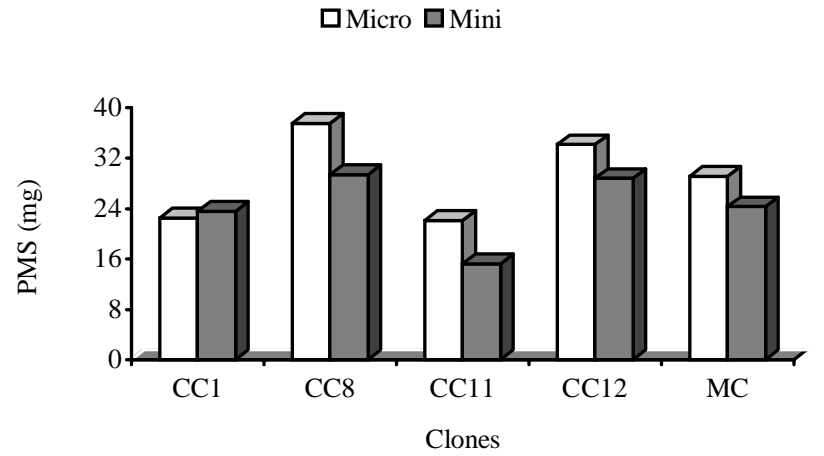

Figura 5 - Peso de matéria seca de raízes (PMS) das microestacas (Micro) e miniestacas (Mini) e médias (MC) de quatro clones de Eucalyptus grandis, aos 28 dias de idade.

Figure 5-Dry weight of roots (PMS) of microcuttings (Micro) and minicuttings (Mini) and overall means (MC) of four Eucalyptus grandis clones, at 28 days of age.

\section{AGRADECIMENTO}

À Empresa Celulose Nipo-Brasileira S.A. (CENIBRA), pela oportunidade da realização do presente trabalho nas dependências do viveiro florestal e pela disponibilização do material genético (clones), e à CAPES (Coordenadoria de Aperfeiçoamento de Pessoal de Ensino Superior), pelo suporte financeiro.

\section{REFERÊNCIAS BIBLIOGRÁFICAS}

AHUJA, M. R. Biotechnology and clonal forestry. In: AHUJA, M. R., LIBBY, W. J. (Eds.). Clonal forestry: genetics and biotechnology. Budapest: Springer-Verlag, 1993. p. 135-144.

ASSIS, T. F. Melhoramento genético do eucalipto. Informe Agropecuário, v. 18, n. 185, p. 32-51, 1996.

ASSIS, T. F.; ROSA, O. P.; GONÇALVES, S. I. Propagação por microestaquia. In: CONGRESSO FLORESTAL ESTADUAL, 7., 1992, Nova Prata. Anais... Santa Maria: UFSM, 1992. p. 824-836.

ASSIS, T. F.; TEIXEIRA, S. L. Enraizamento de plantas lenhosas. In: TORRES, A. C., CALDAS, L. S.; BUSO, J. A. (Eds.). Cultura de tecidos e transformação genética de plantas. Brasília: EMBRAPA-SPI/EMBRAPA-CNPH, 1998. p. 261-296.

BONGA, J. M. Vegetative propagation in relation to juvenility, maturity and rejuvenation. In: BONGA, J. M.; DURZAN, D. J. (Eds.). Tissue culture in forestry. Boston: Martinus Nijhoff, Dr W Junk Publishers, 1982. p.387-412.
BONGA, J. M.; VON ADERKAS, P. In vitro culture of trees. Netherlands: Kluwer Academic Publishers, 1992. $236 \mathrm{p}$.

FRANCLET, A. et al. Rejuvenation. In: BONGA, J. M.; DURZAN, D. J. (Eds.). Cell and tissue culture in forestry. Dordrecht: Kluwer Academic Publishers, 1987. v. 1. p. 232-248.

GEORGE, E. F. Plant propagation by tissue culture - The technology. 6.ed. England: Exegetics , 1993. v. 1. 574 p.

GOMES, A. L. Propagação clonal: princípios e particularidades. Vila Real: Universidade de Trás-osMontes e Alto Douro, 1987. 69 p. (Série Didáctica, Ciências Aplicadas, 1).

GONÇALVES, A. N. Reversão à juvenilidade e clonagem de Eucalyptus urophylla. S. T. in vitro. Piracicaba: ESALQ, 1982. 97 p. Tese (Doutorado em Agronomia) Escola Superior de Agricultura "Luiz de Queiroz”, 1982.

GRATTAPAGLIA, D.; MACHADO, M. A.

Micropropagação. In: TORRES, A. C.; CALDAS, L. S.; BUSO, J. A. (Eds.). Cultura de tecidos e transformação genética de plantas. Brasília: EMBRAPA-SPI/EMBRAPACNPH, 1998. v. 1. p. 183-260.

GREENWOOD, M. S.; HUTCHISON, K. W. Maturation as a development process. In: AHUJA, M. R.; LIBBY, W. J. (Eds.). Clonal forestry: genetics and biotechnology. Budapest: Springer-Verlag, 1993. p. 14-33.

HACKETT, W. P. Juvenility and maturity. In: BONGA, J. M.; DURZAN, D. J. (Eds.). Cell and tissue culture in forestry. Dordrecht: Kluwer Academic Publishers, 1987. v. 1. p. 216-231.

HACKETT, W. P.; MURRAY, J. R. Maturation and rejuvenation in woody species. In: AHUJA, M. R. (Ed.). Micropropagation of woody plants. Dordrecht: Kluwer Academic Publishers, 1993. p. 93-105.

HARTMANN, H. T. et al. Plant propagation: principles and practices. 6.ed. New Jersey: Prentice-Hall, 1997. $770 \mathrm{p}$.

SILVA, L. L. Propagação in vitro de Eucalyptus grandis W. Hill ex Maiden, a partir de gemas epicórmicas. Viçosa, MG: UFV, 1990. 60 p. Dissertação (Mestrado em Ciência Florestal) - Universidade Federal de Viçosa, 1990.

TITON, M. Propagação clonal de Eucalyptus grandis por miniestaquia e microestaquia. Viçosa: UFV, 2001. 65 p. Dissertação (Mestrado em Ciência Florestal) - Universidade Federal de Viçosa, 2001. 
WENDLING, I. Propagação clonal de híbridos de Eucalyptus spp. por miniestaquia. Viçosa, MG: UFV, 1999. 70 p. Dissertação (Mestrado em Ciência Florestal) Universidade Federal de Viçosa, 1999.

WENDLING, I. et al. Propagação clonal de híbridos de Eucalyptus spp. por miniestaquia. Revista Árvore, v. 24, n. 2, p. 181-186, 2000.

XAVIER, A. et al. Desempenho do enraizamento de microestacas e miniestacas de clones híbridos de Eucalyptus grandis. Revista Árvore, v. 25, n. 4, p. 403-411, 2001.
XAVIER, A.; COMÉRIO, J. Microestaquia: uma maximização da micropropagação de Eucalyptus. Revista Árvore, v. 20, n. 1, p. 9-16, 1996.

XAVIER, A.; WENDLING, I. Miniestaquia na clonagem de Eucalyptus. Viçosa, MG: SIF, 1998. 10 p. (Informativo Técnico SIF, 11).

ZOBEL, B. J. Clonal forestry in the eucalypts. In: AHUJA, M. R., LIBBY, W. J. (Eds.). Clonal forestry: conservation and application. Budapest: Springer-Verlag, 1993. p. 139148. 